DURÁN, Mario. "Constitución y legitimación de la pena. Apuntes teleológicos sobre el rol de la Constitución en el sistema penal".

Polít. crim. Vol. 6, № 11 (Junio 2011), Art. 5, pp. 142 - 162.

[http://www.politicacriminal.cl/Vol_06/n_11/Vol6N11A5.pdf]

\title{
Constitución y legitimación de la pena. Apuntes teleológicos sobre el rol de la Constitución en el sistema penal.*
}

\author{
Dr. Mario Durán Migliardi. \\ Doctor en Derecho, Universidad de Salamanca. \\ Profesor de Derecho penal y Criminología, Universidad de Atacama. \\ mduran@uda.cl
}

\section{Resumen}

El presente artículo trata sobre el rol de la Constitución en relación al establecimiento de fin de la pena en un sistema jurídico-penal democrático de Derecho. Para ello, y partiendo de esa premisa, se desarrolla el fundamento constitucional del Derecho penal democrático y la necesidad de justificación del castigo penal, la denominada orientación sustancial o teleológica sobre el rol de la Constitución en el sistema jurídico-penal y el contenido de la Constitución penal, como marco valorativo y axiológico del sistema jurídico-penal.

\section{Palabras clave}

Constitución, derecho penal, fines de la pena.

\begin{abstract}
The present article deals with the role of the Constitution in relation to the establishment of the sanction in a democratic justice criminal system of Law. To achieve so, and having this previous idea as a starting point, the constitutional foundation of the Democratic penal Law is developed, as well as the need of justification of the penal punishment, the so called substantial or teleological orientation about the role of the Constitution in the penal justice system and the content of the penal Constitution as a valorative and axiological framework of the penal criminal justice system.
\end{abstract}

\section{Key words}

Constitution, Penal law, aims of the sanction.

Sumario: 1. Introducción y delimitación: El fundamento constitucional del Derecho penal democrático y la necesidad de justificación del castigo penal. 2. La orientación sustancial o teleológica sobre el rol de la Constitución en el sistema jurídico-penal. 3. El contenido de la Constitución penal, marco valorativo y axiológico del sistema penal. 4. A modo de conclusión: La Constitución y la reforma del sistema jurídico-penal.

\footnotetext{
* Este trabajo ha sido realizado en el marco del Proyecto de iniciación en Investigación Conicyt-Fondecyt 2007 n 11075088 , titulado "Justificación y legitimación de la pena en el Derecho penal chileno. Análisis desde el modelo integral de la ciencia jurídico-penal”, de quien el autor es investigador responsable.
} 
DURÁN, Mario. "Constitución y legitimación de la pena. Apuntes teleológicos sobre el rol de la Constitución en el sistema penal".

\section{Introducción y delimitación: El fundamento Constitucional del Derecho penal democrático.}

Dentro del objetivo general en el que se enmarca este artículo, esto es, intentar analizar la justificación teórica de la aplicación de la pena, su propósito es triple. Por una parte, destacar la importancia que una Constitución social y democrática tiene respecto de la fundamentación de los fines del Derecho penal; justificar a través de dicha Constitución el establecimiento de un sistema de legitimación de la pena $\mathrm{y}$, por último, subrayar la relevancia que una Constitución social y democrática tiene para la reforma del sistema penal en general y para el Derecho penal en particular.

La importancia de ello, como he señalado y justificado latamente en otros trabajos, ${ }^{1}$ radica en que a mi juicio y por diversas razones históricas, jurídico-políticas y, sobre todo, metodológicas, la necesaria visión político-criminal o empírico-valorativa desde la cual se debe justificar la imposición de la pena en nuestro Derecho presenta una aridez motivacional y una escasa profundidad de análisis que, dado nuestro actual estado de desarrollo en otros ámbitos, llama profundamente la atención.

En efecto, si partimos desde la perspectiva valorativa conformada por la moderna estructuración de los principios limitadores al Ius Puniendi en el Estado Social y Demócratico o de la premisa funcionalista acerca del contenido material de la teoría de la Culpabilidad, para la cual, la pena no puede traspasar, ni en su gravedad ni en su duración, el grado de culpabilidad, ${ }^{2}$ comprenderemos que uno de los eslabones sobre los cuales se funda el ejercicio del Ius Puniendi Estatal en un Estado democrático moderno es, precisamente, la justificación del fin en virtud del cual se ha de imponer la sanción punitiva.

Por ello, la determinación de la medida de pena aplicable al caso concreto no se satisface sólo con esbozar la subsunción de los hechos al Derecho para que, en definitiva, se posibilite la determinación -numérica- del quantum o intensidad de la sanción. Por el contrario, para que la aplicabilidad práctica de la pena cobre efectivamente un realce garantista, ha de adscribirse e interrelacionarse en un terreno mixto o ecléctico, en el que inciden no sólo argumentos relativos al hecho delictivo cometido -y que se encuentran

\footnotetext{
${ }^{1}$ Al respecto, DURAN MIGLIARDI, Mario, "El Derecho penal del enemigo. Formulación y observaciones críticas en el contexto del debate sobre la modernización y expansión del Derecho penal" en, CANCIO MELIÁ, Manuel (Ed. Coord.), Derecho penal del enemigo. El discurso penal de la exclusión. Buenos Aires Montevideo: Editoriales B de F; Madrid: Edisofer, 2006. pp. 725 y ss. "Prevención General Positiva o de la Integración. Concepto y función" en: Problemas Actuales del Derecho Penal. Seminario de Derecho Penal Universidad de Salamanca. Libro Homenaje al profesor Dr. Ignacio Berdugo Gómez de la Torre. Santiago: Editorial Jurídica de Santiago, 2007, pp. 269 y ss. "Análisis político-criminal de la ley de responsabilidad penal adolescente y sus modificaciones", en: Estudios de Ciencias Penales: Hacia una racionalización del Derecho Penal. IV Jornadas Nacionales de Derecho Penal y Ciencias Penales, Valdivia, 2007, Santiago de Chile: Legal Publishing, 2008, pp. 275 y ss. "Prevención especial e ideal resocializador. Concepto, evolución y vigencia en el marco de la legitimación y justificación de la pena", Revista de Estudios Criminológicos y Penitenciarios $\mathrm{N}^{\mathrm{o}} 13$, Gendarmería de Chile (2008), pp. 57 y ss.

${ }^{2}$ Vid. ROXIN, Claus, "Reflexiones Político-Criminales Sobre el Principio de Culpabilidad" en: DEL MISMO, Culpabilidad y Prevención en el Derecho Penal. MUÑOZ CONDE, Francisco (Trad.), Madrid: Reus S.A., 1981, pp. 46 y ss.
} 
Polit. crim. Vol. 6, № 11 (Junio 2011), Art. 5, pp. 142 - 162.

[http://www.politicacriminal.cl/Vol_06/n_11/Vol6N11A5.pdf]

vinculados a las normas tradicionales de imputación objetiva-, sino que, además, han de tener injerencia una serie de elementos argumentativos, sustentados en base a reglas y principios que digan relación directa con las diversas teorías sobre los denominados fines de la pena. ${ }^{3}$

Esto supone, político-criminalmente, que al momento de determinarse judicialmente la pena, deben tener vigencia efectiva todos y cada uno de los presupuestos y principios formales y materiales- que inspiran el Porqué y el Para qué de la reacción punitiva ${ }^{4}$. Esto es, una aplicación prospectiva de la determinación judicial de la pena que considere los principios político-criminales limitadores del Ius Puniendi Estatal. ${ }^{5}$

Es por estas razones que, a mi juicio, si se reduce la sustentabilidad y legitimidad de la intervención penal sólo al cumplimiento de normas formales o aspectos meramente simbólicos relacionados con una teoría del delito causalista o tímidamente valorativa, ${ }^{6} \mathrm{se}$ estaría posibilitando la negación o el encubrimiento de uno de los logros teóricos de carácter penal más trascendentales y sobre el cual se sustenta la legitimidad misma de la dogmática jurídico-penal moderna posterior a la II Guerra Mundial: constituir una garantía para el respeto de los derechos fundamentales del ciudadano.

Más aún, si este postulado puede claramente aplicarse en el denominado Derecho penal común o general, en materia de Derecho penal juvenil, sobre todo tomando en consideración los principios socio-educativos, socio-integrativos o resocializadores que lo inspiran, el postulado en comento cobra una importancia trascendental.

Finalmente, aceptado que el punto de partida de la individualización judicial de la pena es la determinación de los fines de la pena, se hace necesario establecer criterios en virtud de los cuales los operadores del sistema judicial puedan justificar -racionalmente- la aplicación de la pena al caso concreto. Así, sobre la base de fines político-criminales claramente definidos, cabría pronunciarse sobre qué hechos son de importancia para la

\footnotetext{
${ }^{3}$ Como expresaba el profesor Bustos Ramírez, al tiempo de determinarse judicialmente la pena "se trata de decidir el quantum de la pena según sea la función que se cree que debe perseguir. Por eso, para tal decisión resultan básicos el sentido y el fin de la pena y, además, los momentos en que la filosofía penal del Estado se manifiesta (constitucional, legal, judicial y administrativo de ejecución de la pena)". BUSTOS RAMÍREZ, Juan, Manual de Derecho Penal. Parte General. $3^{\text {a }}$ Ed.. Barcelona: Ariel, 1989. pp. 394 y ss.

${ }^{4}$ Sobre el problema de la determinación judicial de la pena y la discrecionalidad, Vid. FERRAJOLI, Luigi, Derecho y Razón. Teoría del Garantismo Penal. Madrid: Trotta S.A., 1995, pp. 402 y ss.

${ }^{5}$ En este sentido, se señala que "cuando se decide cuánto castigo a de padecer el reo, es el momento en el que las cuestiones fundamentales sobre el por qué y para qué se le sanciona, han de descender de lo programático a la sentencia concreta. QUINTERO OLIVARES, Gonzalo, "Determinación de la Pena y Política criminal", $C P C \mathrm{~N}^{\mathrm{o}} 4$ (1982), pp. 49 y ss. esp. p. 52; QUINTERO OLIVARES, Gonzalo, "Política criminal y determinación de la pena", en: Doctrina Penal, Buenos Aires, 1982.

${ }^{6}$ Al respecto, SILVA SANCHEZ, Jesús María, "La Teoría de la Determinación de la Pena como Sistema (Dogmático): Un Primer Esbozo.”, InDret No 2 (2007), pp. 4 y ss. ZIFFER, Patricia, "Consideraciones Acerca de la Problemática de la Individualización de la Pena", en: AA.VV., Determinación Judicial de la Pena, Buenos Aires: Editores del Puerto, 1993, p. 91.
} 
DURÁN, Mario. "Constitución y legitimación de la pena. Apuntes teleológicos sobre el rol de la Constitución en el sistema penal".

individualización de la pena en el caso concreto y como éstos deben valorarse si hubiera lugar a ello. ${ }^{7}$

Así, para abordar los temas señalados, examinare las principales orientaciones existentes en la doctrina en torno al rol de la Constitución Política respecto del sistema penal, haciendo especial mención a la orientación sustancial, teleológica o constitucional. Asimismo, analizare la denominada Constitución penal y su carácter de marco valorativo y axiológico para el sistema penal en general, tomando como ejemplo la Constitución Española de 1978. Por último, a manera de conclusión, examinare el rol de la Constitución en la reforma del sistema penal y del Derecho penal.

\section{La orientación sustancial o teleológica sobre el rol de la Constitución en el sistema penal.}

En la moderna doctrina penal pueden distinguirse dos grandes enfoques desde los cuales se ha emprendido el análisis del rol de la Constitución política respecto del sistema penal y su reforma: la orientación sistemática o dogmática-penal y la orientación sustancial o constitucional. ${ }^{8}$

Entre las principales diferencias que distinguen a ambas orientaciones debe destacarse el rol que éstas le asignan a la Constitución Política en el marco del sistema penal. ${ }^{9}$

Así, para la orientación sistemática o dogmática-penal, el rol de la Constitución es, básicamente, limitar el poder del Estado en materia penal y garantizar los derechos del individuo, esto es, construir principios capaces de restringir el siempre excesivo e insaciable Ius puniendi Estatal. Por ello, esta orientación se satisface con establecer principios limitadores como el de legalidad, el de responsabilidad personal o el de culpabilidad que, extraídos del Derecho natural o de programas políticos, se caracterizan por ser externos al Derecho penal. Por esta razón, además, la reforma del sistema penal

\footnotetext{
7 Al respecto, en detalle, JESCHECK, Hans-Heinrich, Tratado de Derecho Penal. Parte General. MANZANARES SAMANIEGO, José Luis (Trad.), Granada: Comares. 1993, pp. 790 y ss. MAGARIÑOS, Mario, "Hacia un Criterio Para la Determinación Judicial de la Pena", en; AA.VV., Determinación Judicial de la Pena, cit. nota ${ }^{\circ}$ 6, pp. 74 y ss. ROXIN, Claus, "La Determinación de la Pena a la Luz de la Teoría de los fines de la Pena", en: DEL MISMO, Culpabilidad y Prevención en el Derecho Penal, cit. nota $\mathrm{n}^{\circ} 2$, pp. 46 y ss. ZIFFER, "Consideraciones Acerca de la Problemática”, cit. nota no 6, pp. 91 y ss.

${ }^{8}$ En un sentido similar, BERDUGO/ARROYO/GARCÍA/FERRÉ/SERRANO, Lecciones de Derecho penal. Parte General, $2^{\mathrm{a}}$ Ed. Barcelona: Praxis, 1999, pp. 39 y ss.; GARCÍA RIVAS, Nicolás, El poder punitivo en el Estado democrático de Derecho. Cuenca: U. de Castilla-La Mancha, 1996, p. 43. Sobre la relación entre el Derecho constitucional y el Derecho penal, desde la óptica dogmática-penal, Cfr. TIEDEMANN, Klaus, "Constitución y Derecho penal", REDC N 33 (1991), pp. 145-171. Para un análisis particular sobre la orientación sustancial o teleológica y su visión sobre las relaciones entre Constitución-Derecho penalCriminología y realidad social; DURAN MIGLIARDI, Mario, Introducción a la Ciencia jurídico-penal contemporánea. Santiago: Ediciones Jurídicas de Santiago, 1996.

${ }^{9}$ En este sentido, Cfr. DONINI, Massimo, "Un Derecho penal fundado en la carta constitucional: razones y límites. La experiencia italiana” en: VV.AA. Responsa Iurisperitorum Digesta. Vol. II. Salamanca: Edic. Universidad, 2001, pp. 223 y ss. Para un análisis pormenorizado, Cfr. DONINI, Massimo, Il volto attuale dell'illecito penale. La democracia penale tra differenzizione e sussidiarietà. Milán: Giuffrè, 2004, pp. 61 y SS.
} 
queda aquí entregada casi exclusivamente a la elaboración de la propia dogmática jurídicopenal.

La relación entre la Constitución y el sistema penal sería aquí, más bien, una relación negativa, por cuanto ésta definiría qué clases de incriminaciones pueden ser legítimas y qué bienes jurídicos deben quedar al margen de la intervención penal, qué técnicas de tutela penal no pueden adoptarse y qué sanciones no son admisibles en el Derecho penal. ${ }^{10}$

Para la orientación sustancial o constitucional, en cambio, el poder punitivo del Estado debe estar definido y fundado en la Constitución, no sólo en cuanto a sus fines, objetivos e instrumentos, sino que, además, en cuanto a los postulados o principios de su sistema de argumentación y aplicación, es decir, su faz legislativa y judicial. Por ello, esta orientación postula, a diferencia de la anterior, que los principios rectores del sistema penal no son meros límites al Ius puniendi, sino verdaderos fundamentos o principios constituyentes del mismo, esto es, un Derecho penal Constitucional cuya función esencial es garantizar los valores, bienes y derechos que en dicho texto se establecen. Por ello, es en la propia Constitución social y democrática de Derecho donde se encuentra el cuadro de valores y la jerarquía de bienes a los que el legislador debe atenerse para elaborar los intereses dignos de tutela penal. ${ }^{11}$

Por estas razones, y partiendo de la base que la intervención del Derecho penal siempre afecta derechos fundamentales y que las libertades sólo pueden limitarse a través del Derecho penal si éste tiene por finalidad proteger esas mismas libertades, sólo los bienes de relevancia constitucional pueden justificar dicho sacrificio. Así, para esta orientación, resulta sumamente inadecuado afectar los derechos constitucionales para proteger bienes inexistentes o de inferior rango. Sobre todo, porque la Constitución social y democrática establece precisamente -como veremos- un sistema de valores donde el poder punitivo se encuentra limitado, más que formalmente, por la legitimidad del pacto constituyente que reconoce y establece dichos derechos fundamentales. ${ }^{12}$

\footnotetext{
${ }^{10}$ Cfr. DONINI, “Un Derecho penal fundado”, cit. nota n ${ }^{\circ}$ 9, p. 224.

${ }^{11}$ En este sentido, Cfr. BRICOLA, Franco, “Teoria generale del reato" en: Scritti di Diritto Penale. Vol. I, Tomo I. Milán: Giuffrè, 1997, pp. 539 y ss.; MOCCIA, Sergio, Il Diritto penale tra essere e valore. Funzione sistematica teleologica. Nápoles: ESI, 1992; DONINI, Massimo, Teoria del reato. Una introduzione. Padova: Cedam, 1995; DEL MISMO, "Dogmatica penale e política criminal a orientamento costituzionalistico. Conoscenza e controllo critico delle secelte di criminalizzazione”, Dei delitte e delle pene No 3 (1998), pp. 37 y ss.

${ }_{12}$ Al respecto, véase arriba el apartado sobre el planteamiento teleológico del DP de la Esc. de Bologna. Particularmente, sobre la relevancia de la norma constitucional en materia penal y la preeminencia abso-luta de la libertad personal en el ámbito de los valores constitucionales, Cfr. BRICOLA, "Teoria generale del reato", cit. nota $\mathrm{n}^{\mathrm{o}} 11$, pp. 565 y ss. En el mismo sentido, Cfr. ANGIONI, Francesco, "Beni costituzionali e criteri orientativi sull'area dell'illecito penale' " en: STILE, Alfonso (a cura di), Bene Giuridico e Riforma della parte speciale. Nápoles: Jovene, 1985, pp. 57-130, esp. pp. 88 y ss; CARBONELL MATEU, Juan Carlos, Derecho penal: concepto y principios constitucionales. $3^{\mathrm{a}}$ Ed., Valencia: Tirant Lo Blanch, 1999, p. 36. Sobre la crisis de la capacidad selectivo-sustancial del vínculo constitucional, respecto de la política de bienes jurídicos y las técnicas de tutela, así como del propio concepto sustancial de delito y su relación con el modelo de sociedad y los cambios político-electorales, Cfr. DONINI, Il volto attuale dell'illecito penale, cit. nota $\mathrm{n}^{\circ} 9$, p. 70 .
} 
DURÁN, Mario. “Constitución y legitimación de la pena. Apuntes teleológicos sobre el rol de la Constitución en el sistema penal".

Así, como bien se señala, es con referencia a la Constitución, en sus conexiones técnicojurídicas y valorativas con el sistema penal, como se debe establecer el concepto y el método del Derecho penal, el concepto de delito, el fin de las penas y el sentido de la dogmática y del sistema. ${ }^{13}$ Esto significa, en un Estado social y democrático de Derecho, que el Derecho penal, como parte del ordenamiento jurídico, debe adaptarse y ponerse en consonancia con dicho modelo de Estado así como con los valores que éste propugna ya que la legitimidad del Derecho penal o del poder punitivo del Estado proviene del modelo fijado en la Constitución. ${ }^{14}$

Más aún, en este sentido, la propia reforma penal -desde la óptica sustancial o constitucional, como veremos más adelante- queda entregada no sólo a la dogmática jurídico-penal sino también a la Política Criminal, abriendo una perspectiva metodológica pluridimensional, abierta al ser y al dialogo entre las cuestiones sustanciales, las categorías sistemáticas y los objetivos político-criminales. Ampliando, de esta forma, las posibilidades teóricas y prácticas para la evolución del sistema y la reforma penal al no hacerla depender -de manera exclusiva y excluyente- del desarrollo, tradicionalmente de sistemática endógena, esto es, interna, cerrada y autónoma de dicha dogmática, incorporando a este proceso todo un abanico de valoraciones y nuevos instrumentos. ${ }^{15}$

Por ello, puede afirmarse que el enfoque constitucionalista del Derecho penal va más allá de la simple idea de que éste no debe contradecir la Constitución -lo que, por obvio, esta fuera de discusión- puesto que plantea, desde otra perspectiva, que la Constitución más que un mero límite es el fundamento de la pena y del Derecho penal. ${ }^{16}$ Así, como bien se señala, tanto el establecimiento de las sanciones penales como la elección de la conducta a sancionar, no pueden ser decisiones entregadas al simple capricho del legislador sino que debe tratarse de decisiones fundamentadas directamente en algunas de las características del ilícito o de la sanción penal, de acuerdo a las propias condiciones o requisitos que establezca la respectiva norma constitucional en materia penal. ${ }^{17}$

\footnotetext{
13 Cfr. ARROYO ZAPATERO, Luis, "Fundamento y función del sistema penal: el programa de la Constitución" RJCLM N 1 (1987), pp. 97-112, esp. p. 99.

${ }^{14}$ En este sentido, Cfr. MUÑOZ CONDE, F. - GARCÍA ARÁN, M. Derecho penal PG. Valencia: Tirant Lo Blanch, 1994, p. 64.

${ }^{15}$ Al respecto, Cfr. MOCCIA, Sergio, "Función sistemática de la política criminal. Principios normativos para un sistema penal orientado teleológicamente" en: SCHÜNEMANN, B.-De FIGUEIREDO DIAS, J. (Coords.) SILVA SÁNCHEZ, J.M. (Ed. Española) Fundamentos de un Sistema Europeo del Derecho penal. LibroHomenaje a Claus Roxin. Barcelona: Bosch, 1995, pp. 73 y ss. Sobre el valor axiológico de la constitución como marco de referencia valorativo de la política criminal, Cfr. ZÚÑIGA RODRÍGUEZ, Laura, Política criminal, Madrid: Colex, 2001, p. 50-55.

${ }^{16}$ Cfr. DONINI, "Un Derecho penal fundado", cit. nota $n^{\circ} 9$, p. 223.

17 Cfr. BRICOLA, "Teoria generale del reato", cit. nota $\mathrm{n}^{\circ}$ 11, pp. 554-560. Así, para Bricola, la individualización de los rasgos sustanciales del ilícito penal -que brotan del análisis normativo- no sólo sirve para limitar la elección pre-normativa del legislador, sino que también para entender, en el marco del Estado de Derecho, fenómenos como el aumento gradual y constante del número de los ilícitos sancionados penalmente o el proceso de transformación del ilícito administrativo en ilícito penal.
} 


\section{Polit. crim. Vol. 6, № 11 (Junio 2011), Art. 5, pp. 142 - 162. \\ [http://www.politicacriminal.cl/Vol_06/n_11/Vol6N11A5.pdf]}

De esta forma, puede señalarse que la Constitución política -desde esta perspectiva- cumple determinadas funciones en el ámbito del sistema penal. ${ }^{18}$ Dentro de las que destacan, entre otras, la de influir directamente en la práctica jurídica a través de los supuestos concretos que se presentan ante los Tribunales de justicia. Ello, principalmente, porque los Tribunales deben tener presente lo dispuesto en la Constitución para los efectos de aplicarlo directamente o de interpretar, de acuerdo con la misma, los preceptos ordinarios que requieran de una adecuación hermenéutica respecto del texto constitucional, de forma tal que toda contradicción entre éstos y la Constitución democrática debe resolverse a favor de esta última. $^{19}$

En segundo lugar, la Constitución cumpliría una función de orientación de la concreta política-penal a desarrollar por el Estado. Esto es, que la Constitución, dentro de su propio marco político-criminal general y de sus valores y principios, puede establecer o promocionar determinadas sanciones y figuras penales que deben tenerse en cuenta por el legislador en el futuro. ${ }^{20}$

Por último, la Constitución tendría una importante función doctrinal pues permite la elaboración de teorías en relación con la interpretación de la ley, la teoría del delito, el bien jurídico, la teoría de la pena o la propia reforma del sistema penal. ${ }^{21}$ Más aún, en este sentido, dado los múltiples efectos teóricos y prácticos que implica adoptar una u otra postura, el grado de aceptación que se tenga acerca de la penetración e influencia de la Constitución sobre el Derecho penal se refleja claramente -como veremos más adelante- a la hora de abordar dichas cuestiones. ${ }^{22}$

Establecida la visión sustancial o teleológica respecto del rol de la Constitución respecto del Derecho penal, corresponde examinar el contenido de la denominada Constitución penal y su importancia como marco valorativo y axiológico de justificación del sistema penal y del sistema de verificación.

\footnotetext{
${ }^{18}$ En este sentido, Cfr. ESCRIVÁ GREGORI, José María, “Algunas consideraciones sobre Derecho penal y Constitución" Papers No 13, pp. 147-149; VIVES ANTÓN, "Reforma política y Derecho penal” en su obra, La libertad como pretexto. Valencia: Tirant Lo Blanch, 1995, pp. 71 y ss., esp. pp. 119 y ss.

${ }^{19} \mathrm{Al}$ respecto, resulta de suma importancia lo prescrito en el Art.9 apartados $1^{\mathrm{o}}$ y $3^{\mathrm{o}}$ de la CE en cuanto a la sujeción de los poderes públicos a la Constitución y a la garantía de la jerarquía normativa, la seguridad jurídica y la responsabilidad e interdicción de la arbitrariedad de los poderes públicos.

${ }^{20}$ Así, entre otros, en los Arts.18, 24.1, 33, 35, 45 y 46 de la CE se anuncia el establecimiento de sanciones penales con el fin de proteger la intimidad por el uso de la informática; la tutela efectiva y evitar la indefensión; la utilidad social o cultural de la propiedad; contra la discriminación en el empleo; para la defensa del medio ambiente; y para proteger el patrimonio histórico, cultural y artístico de los pueblos de España. Para una completa relación al respecto, Cfr. BUENO ARÚS, F., "Las normas penales en la Constitución española de 1978", Doctrina Penal No 8 (1979), pp. 821 y ss. Sobre los efectos directos e indirectos y las limitaciones recíprocas entre la CE y el Derecho penal, Cfr. ARROYO ZAPATERO, Luis, "Control constitucional del Derecho y de la justicia penal", $C P C \mathrm{~N}^{\mathrm{o}}$ XVII (1982), pp. 285 y ss.

${ }^{21}$ Baste señalar al respecto el cúmulo de interpretaciones, polémicas y doctrinas que se han derivado del Art.25.2 de la CE que establece que las penas y las medidas de seguridad estarán orientadas hacia la reeducación y reinserción social y no podrán consistir en trabajos forzados.

${ }^{22}$ En este sentido, Cfr. GARCÍA RIVAS, El poder punitivo en el Estado, cit. nota nº 8, p. 43.
} 
DURÁN, Mario. "Constitución y legitimación de la pena. Apuntes teleológicos sobre el rol de la Constitución en el sistema penal".

\section{El contenido de la Constitución penal, marco valorativo y axiológico del sistema penal.}

Establecida la intima relación entre la Constitución y el Derecho penal así como la importancia de ésta en la configuración del conjunto de valores-marco, de los fines $\mathrm{u}$ objetivos y de los instrumentos y técnicas en los que se sustenta y desarrolla el sistema penal, nos queda por resaltar la necesidad de que el conjunto del sistema penal se adecue y oriente en función de la Constitución. ${ }^{23}$

La necesidad de que el sistema penal se adecue y oriente a la Constitución surge, más allá de los imperativos formales que exige la jerarquía normativa, sobre todo cuando ésta se constituye como el fundamento racional y legítimo de la convivencia social al reconocer y positivizar, no sólo el código de valores imperantes en la sociedad, sino aquellos derechos y garantías que posibilitan a los ciudadanos su desarrollo y la resolución democrática del conflicto entre el Estado y el individuo.

Evidentemente, esta necesidad de adecuación sólo es posible en un contexto socio-cultural que reconozca tanto la directa influencia de la política en el Derecho penal -y la transparente- como el principio de que dentro de la historia del Estado moderno subyace la historia del propio Derecho penal. ${ }^{24}$ Esto es, en un contexto político y social que sólo otorgue legitimidad democrática a la política-criminal desarrollada por el Estado en la medida que la vocación social y democrática del sistema penal impuesto por la Constitución, que obligue al legislador a articular los medios de protección jurídico-penal de acuerdo a los valores e intereses colectivos, se vea reflejado en el sistema penal.

Precisamente por estas razones, la noción de la Constitución del Estado social y democrático de Derecho es la que sirve de ejemplo para demostrar el real alcance y significado que la denominada orientación sustancial tiene sobre el rol de la Constitución Política para con el sistema penal y su reforma. ${ }^{25}$ Más aún, a mi juicio, estas ideas sirven

\footnotetext{
${ }^{23}$ Sobre la discrepancia entre una nueva constitución democrática y un CP autoritario, resp. de España, Cfr. ESCRIVÁ GREGORI, "Algunas consideraciones sobre Derecho penal”, cit. nota no 18, pp. 146-147; TERRADILLOS BASOCO, Juan, "Constitución y ley penal. La imposible convergencia", RFDUCM T. 1011 (1986), pp. 651 y ss; LÓPEZ BARJA DE QUIROGA, Jacobo, “Constitución y Derecho penal”, $C P C \mathrm{~N}^{\circ}$ 31-33 (1987), p. 55 y ss. resp. de Italia, Cfr. "Il Codice Rocco cinquant'anni dopo" en: La Questione Criminale. 1981. Edición temática sobre el tema con múltiples artículos.

${ }^{24}$ Al respecto, Cfr. BARBERO SANTOS, Marino, Política y Derecho Penal en España. Madrid: Tucar Ediciones, 1977; VIVES ANTÓN, "Reforma política y Derecho penal”, cit. nota no 18, pp. 71 y ss; QUINTERO OLIVARES, Represión penal y Estado de Derecho, Barcelona: Dirosa, 1976, pp. 30 y ss; BUSTOS RAMÍREZ, J.-HORMAZÁBAL MALARÉE, H., "Pena y Estado"; DE SOLA DUEÑAS, Ángel, "Desarrollo democrático y alternativas político criminales", ambos en Papers $\mathrm{N}^{\circ}$ 13, pp. 97 y ss, y pp. 215 y ss., resp; MIR PUIG, Santiago, "Función de la pena y teoría del delito en el Estado social y democrático de Derecho" en su obra, El Derecho penal en el Estado social y democrático de Derecho. Ariel: Barcelona, 1994, pp. 31-34.

${ }^{25}$ Sobre el concepto material de delito, el Estado social y democrático y las orientaciones de la CE, Cfr. TERRADILLOS BASOCO, Juan, "La satisfacción de necesidades como criterio de determinación del objeto de tutela jurídico-penal”, RFDUCM No 63 (1981), pp. 123-149, esp. pp. 141-144. Una evaluación al respecto en GARCÍA ARÁN, Mercedes, "Constitución y Derecho penal, veinte años después" en: ARROYO, L.BERDUGO, I. (Dir). Homenaje al Dr. Marino Barbero Santos. Cuenca: U. De Castilla La Mancha-U. De Salamanca, 2001, pp. 285 y ss.
} 
para afirmar, por una parte, la importancia que una Constitución social y democrática tiene respecto de la fundamentación del propio Derecho penal, y por otra, para justificar el establecimiento de un sistema de verificación del Derecho penal democrático, que sirva no sólo para comprobar la consolidación y correcta aplicación de los valores y principios establecidos en la Constitución sino para proponer las reformas necesarias tendientes al establecimiento de éstos en los sistemas penales que aún no los incorporan.

Ello, sobre todo porque, como bien se señala, la conexión entre lo penal y lo político no se reduce sólo a una vinculación entre la ley positiva y la ideología dominante -aun cuando ello sea el dato inmediatamente aprensible- sino que debe alcanzar, y de hecho así sucede, a la explicación o crítica científica de los preceptos positivos o de las convicciones dominantes. Así, por esta razón, del mismo modo que se afirma que las leyes penales positivas son en buena medida fruto de convicciones dominantes, también es preciso aceptar que la crítica a las instituciones penales no puede hacerse eficazmente sin la referencia a un desideratum político, pues de lo contrario se operaría en la crítica un divorcio inexistente en la realidad jurídico-positiva. ${ }^{26}$

Más aún, la dinámica Constitucional en el ámbito penal no se limita a determinar la prohibición de construcciones interpretativas o dogmáticas que supongan una contradicción con los valores y preceptos constitucionales, por el contrario, la propia construcción dogmática debe estar al servicio de una elaboración coherente y sistemática de lo particular con lo general, de los preceptos concretos con los principios generales. Por ello, por una exigencia de la lógica jurídica derivada del valor normativo superior de la constitución democrática, la propia teoría del delito y de la pena deben inspirarse en los principios de la constitución. $^{27}$

De esta forma, para esta sistemática cobra una importancia trascendental el planteamiento según el cual, tanto los principios generales de la Constitución, como algunos preceptos de ésta, configuran un verdadero Derecho penal constitucional, ${ }^{28}$ que contiene un verdadero sistema de valores compuesto no sólo por los derechos fundamentales, sino por los derechos de los ciudadanos, los valores que de ellos emanan, y aquellos que son necesarios y convenientes para hacerlos efectivos, sean éstos los derechos fundamentales de la persona o los derechos que se deriven del desarrollo de éstos. ${ }^{29}$ Planteamiento jurídico que, además, puede perfectamente fundamentarse -tanto filosófica como sociológicamente- en el Sistema

\footnotetext{
${ }^{26}$ Cfr. QUINTERO OLIVARES, Represión penal y Estado de Derecho, cit. nota n ${ }^{\circ}$ 24, p. 22.

${ }^{27}$ Cfr. ARROYO ZAPATERO, “Control constitucional del Derecho”, cit. nota no 20, p. 389.

28 Así, BRICOLA, "Teoria generale del reato", cit. nota no 11, pp. 539 y ss; BERDUGO/ARROYO/GARCÍA/FERRÉ/SERRANO, Lecciones de Derecho penal, cit. nota $\mathrm{n}^{\circ} 8, \mathrm{pp} .39 \mathrm{y}$ ss; CARBONELL MATEU, Derecho penal: concepto y principios constitucionales, cit. nota $\mathrm{n}^{\circ} 12$, pp. 83 y ss. En este sentido, aplicado a la dogmática jurídico-penal, Cfr. MIR PUIG, "Función de la pena y teoría del delito", cit. nota $n^{\circ}$ 24, pp. 29-112; HORMAZÁBAL MALARÉE, Hernán, Bien jurídico y Estado social y democrático de Derecho (El objeto protegido por la norma penal), Barcelona: PPU, 1991, pp. 139 y ss. esp. 169 y ss; GONZÁLEZ RUS, Juan José, Bien jurídico y Constitución (Bases para una teoría), Madrid: Fundación Juan March, 1983, pp. 23 y ss., esp. 32 y ss; CÓRDOBA RODA, Juan, "La pena y sus fines en la constitución Española de 1978", Papers No 13, pp. 129 y ss.

${ }^{29}$ En este sentido, CARBONELL MATEU, Derecho penal: concepto y principios constitucionales, cit. nota $\mathrm{n}^{\mathrm{o}} 12$, p. 37.
} 
DURÁN, Mario. "Constitución y legitimación de la pena. Apuntes teleológicos sobre el rol de la Constitución en el sistema penal".

de los Derechos postulado, desde la óptica de la Teoría Discursiva de los Derechos Humanos, por Jürgen Habermas. ${ }^{30}$

Así, el contenido del Derecho penal constitucional estaría dado, en primer lugar, por los principios generales consagrados por la Constitución y que tienen gran relevancia para el sistema penal, esto es, los valores superiores de libertad, igualdad, pluralismo y justicia, consagrados en el Art. $1^{\mathrm{o}}$ de la Constitución Española de $1978,{ }^{31}$ así como los principios generales de racionalidad, proporcionalidad y promoción de la libertad y de la igualdad, real y efectiva, establecidos en el Art. $9^{\circ}$ de la misma. ${ }^{32}$ De igual forma, a mi juicio, resulta destacable la norma de interpretación del Art. 10.2 que obliga a interpretar los Derechos fundamentales y libertades reconocidos por la Constitución de acuerdo con la Declaración Universal de los Derechos Humanos y los tratados y acuerdos internacionales sobre las mismas materias suscritos por España. ${ }^{33}$

En segundo lugar, el Derecho penal constitucional estaría integrado por aquellos preceptos constitucionales sobre mandatos, prohibiciones y regulaciones que afectan directamente al Derecho penal, entre los que se encuentran, fundamentalmente, los artículos 15, 17, 24 y 25 de la Constitución Española. Esto es, la proscripción de la tortura, de las penas y tratos

30 Dicho sistema articula los Derechos fundamentales -desde la Teoría discursiva- en conexión con la soberanía popular, postulando la legitimidad a partir de la legalidad a través de dos tareas; institucionalizar una formación racional de la voluntad política y garantizar el lenguaje en el que ésta pueda expresarse como voluntad común de los miembros de una comunidad jurídica libremente asociada. Por ello, el sistema de derechos (similar al catálogo de derechos civiles, políticos y sociales) contiene cinco categorías, donde sólo las tres primeras son principios jurídicos que orientan al legislador: el derecho a iguales libertades subjetivas de acción, los derechos de pertenencia a una comunidad jurídica y las garantías procesales. Sin éstos no hay derecho legítimo. La $4^{\mathrm{a}}$ son los derechos políticos a participar con igualdad de oportunidades en procesos de formación de la opinión y la voluntad comunes, en los que los ciudadanos ejerzan su autonomía política y establezcan derecho legítimo. La $5^{\mathrm{a}}$ son los Derechos a que se garanticen condiciones de vida que, social, técnica y ecológicamente, aseguren un disfrute en términos de igualdad de oportunidades de los derechos civiles antes señalados. HABERMAS, Jürgen, Facticidad y validez. Sobre el derecho y el Estado democrático de derecho en términos de teoría del discurso. Introd. y Trad. sobre la $4^{\circ}$ edic. revisada de Manuel Jiménez Redondo. Madrid: Trotta, 2001, pp. 184-197.

${ }^{31}$ En este sentido, el Tribunal Constitucional ha declarado, en el fundamento jurídico $4^{\circ}$ de la STC 19/1988 de 16 de febrero, que el Principio de culpabilidad se dice implícitamente consagrado por la Constitución al elevarse en ella la justicia a condición de valor superior del ordenamiento jurídico en su Art. $1^{\circ}$. 1 . Más aún, en el fundamento jurídico $4^{\circ}$ de la STC 150/1991 de 04 de julio, el Tribunal Constitucional ha señalado que la CE consagra sin duda el Principio de culpabilidad como principio estructural básico del Derecho penal, de manera que no sería constitucionalmente legítimo un Derecho penal 'de autor' que determinara las penas en atención a la personalidad del reo y no según la culpabilidad de éste en la comisión de los hechos. Respecto del principio de culpabilidad y la Constitución, Cfr. GARCÍA RIVAS, El poder punitivo en el Estado, cit. nota $\mathrm{n}^{\circ}$ 8, pp. 56 y ss.; BACIGALUPO, Enrique, "La jerarquía constitucional del principio de culpabilidad" en, DEL MISMO, Principios Constitucionales de Derecho penal. Buenos Aires: Hammurabi, 1999, pp. 137151.

${ }^{32} \mathrm{Cfr}$. BERDUGO/ARROYO/GARCÍA/FERRÉ/SERRANO, Lecciones de Derecho penal, cit. nota $\mathrm{n}^{\mathrm{o}} 8$, p. 41. En el mismo sentido, Cfr. ESCRIVÁ GREGORI, "Algunas consideraciones sobre Derecho penal”, cit. nota $\mathrm{n}^{\circ} 18$, p. 148.

33 Sobre la interpretación constitucional y la aplicación de los Derechos fundamentales, Cfr. PÉREZ LUÑO, Antonio, Derechos Humanos, Estado de Derecho y Constitución. Madrid: Tecnos, 4 Ed., 1991, pp. p. 284 y ss; VIVES ANTÓN, "Reforma política y Derecho penal", cit. nota n ${ }^{\circ} 18$, pp. 76 y ss.; BACIGALUPO, Enrique, "Protección de los Derechos fundamentales por la jurisdicción constitucional y por el poder judicial" en, DEL MISMO, Principios Constitucionales de Derecho penal, cit. nota n ${ }^{\circ}$ 31, pp. 13-39. 
inhumanos y degradantes, y la abolición de la pena de muerte (Art.15); la consagración de las garantías de la libertad personal frente a la privación de la libertad, con cláusulas expresas sobre la detención preventiva y la prisión provisional (Art.17); la formulación de un catalogo de garantías que integran el derecho a la tutela judicial efectiva y a un proceso con todas las garantías, con expresa consagración de la presunción de inocencia (Art.24); la proclamación del principio de legalidad y de irretroactividad en materia sancionatoria, ${ }^{34}$ y de la proscripción de la privación de libertad en el ámbito del poder sancionador de la Administración (Art.25). Tema aparte es la consagración de un fin de la pena, junto con la prevención del delito, como es el principio de resocialización. ${ }^{35}$

En tercer lugar, constituirían también Derecho penal constitucional aquellos preceptos que consagran los derechos fundamentales y que, por consiguiente, delimitan el Ius Puniendi, vinculando tanto al poder legislativo como al judicial. Este catálogo de derechos fundamentales adquiere especial importancia en tanto que, por una parte, constituye el núcleo específico de legitimación del ordenamiento de bienes jurídicos del sistema penal con efectos de legitimación y límite de la intervención penal y, por otra, delimita lo punible cuando se trata de acciones típicas que se fundamentan en el ejercicio de tales derechos fundamentales. ${ }^{36}$

Dentro de tales derechos fundamentales pueden destacarse, ${ }^{37}$ particularmente, los relativos a la igualdad (Art.14); ${ }^{38}$ a la vida y a la integridad física (Art.15) $;^{39}$ a la libertad ideológica

34 Al respecto, con mención a la 'ley penal en blanco' y al ne bis in idem, Cfr. GARCÍA RIVAS, El poder punitivo en el Estado, cit. nota $\mathrm{n}^{\circ}$ 8, pp. 68 y ss.; BACIGALUPO, Enrique, "El principio de legalidad como tarea inconclusa", "La garantía del principio de legalidad y la prohibición de la analogía en el Derecho penal”, "La problemática Constitucional de las leyes penales en blanco" todos en, DEL MISMO, Principios Constitucionales de Derecho penal, cit. nota $\mathrm{n}^{\circ}$ 31, pp. 43-72, 75-96, 99-111, resp. Sobre el principio de legalidad en la CE, Cfr. BUSTOS RAMIREZ/HORMAZÁBAL MALARÉE, Lecciones de Derecho penal, Vol. I, Madrid: Trotta, 1997, pp. 83 y ss.

35 Al respecto, Cfr. MIR PUIG, "Función de la pena y teoría del delito", cit. nota no 24, pp. 36-50; CÓRDOBA RODA, Juan. "La pena y sus fines", cit. nota n ${ }^{\circ} 28$, pp. 129 y ss. Sobre la teoría de la pena, sus límites, la prevención y la función psicológica, Cfr. ESCRIVÁ GREGORI, "Algunas consideraciones sobre Derecho penal", cit. nota $\mathrm{n}^{\circ} 18$, pp. 159 y ss. Sobre el principio de resocialización y la función constitucional de la pena, la medida de seguridad y las alternativas a la prisión, Cfr. GARCÍA RIVAS, El poder punitivo en el Estado, cit. nota ${ }^{\circ}$ 8, pp. 46-53. Para una visión crítica respecto al tema, Cfr. GARCÍA-PABLOS, Antonio, “La 'resocialización' del delincuente.¿Un Mito?” en, EL MISMO, Problemas actuales de la criminología. Madrid: Publicación del Instituto de criminología de la U. Complutense de Madrid, 1984, pp. 203 y ss.; DEL MISMO, "La supuesta función resocializadora del Derecho Penal: utopía, mito y eufemismo", $A D P C P$ T.XXXII, fascículo III (1979), pp. 645 a 700; MUÑOZ CONDE, Francisco, "La resocialización del delincuente. Análisis y crítica de un mito", CPC No 7 (1979); DEL MISMO, Derecho Penal y Control Social. Jerez de la Frontera: Fundación Universitaria de Jerez, 1986, p. 89 y ss.; TERRADILLOS BASOCO, Juan, “Constitución y ley penal. La imposible convergencia”, RFDUCM, T. 10-11 (1986), p.655-657.

36 Sobre el principio de exclusiva protección de bienes jurídicos, la lesividad del hecho y la teoría constitucional del bien jurídico, Cfr. VIVES ANTÓN, "Reforma política y Derecho penal", cit. nota nº 18, pp. 97-101; GARCÍA RIVAS, El poder punitivo en el Estado, cit. nota no 8, pp. 46-53; HORMAZÁBAL MALARÉE, Bien jurídico y Estado social, cit. nota $n^{\circ} 28$, pp. 139 y ss. esp. 169 y ss.; GONZÁLEZ RUS, Bien jurídico y Constitución, cit. nota no 28, pp. 23 y ss. esp. 32 y ss.; ÁLVAREZ GARCÍA, Fernando, "Bien jurídico y Constitución", CPC (1991), pp. 18 y ss.; AGUADO CORREA, Teresa, El principio de proporcionalidad en Derecho penal. Madrid: Edersa, 1999, pp. 160 y ss.

37 Sobre éstos, otros derechos y aspectos generales de la CE, Cfr. VV.AA. RFDUCM: "Diez años de desarrollo constitucional". Monográfico nº 15 (1989). 
DURÁN, Mario. "Constitución y legitimación de la pena. Apuntes teleológicos sobre el rol de la Constitución en el sistema penal".

y religiosa (Art.16); a la libertad personal (Art.17); al honor y a la intimidad (Art.18); ${ }^{40}$ a la libre expresión y a la libertad de prensa (Art.20); ${ }^{41}$ a los derechos de reunión (Art.21); de asociación (Art.22); y a la libertad sindical y al derecho de huelga (Art.28).

Por último, el Derecho penal constitucional estaría integrado por los preceptos constitucionales que regulan de forma expresa conceptos pertenecientes al sistema penal. Entre ellos se encuentran, por ejemplo, los que regulan la inviolabilidad y la inmunidad parlamentaria (Art.71); el principio de unidad jurisdiccional (Art.117); la publicidad del proceso penal y la necesaria motivación de las sentencias (Art.120); la acción popular (Art.125) y la policía judicial (Art.126).

Finalmente, se postula la existencia de una cláusula general de cierre del contenido del Derecho penal Constitucional, constituido por el principio de interpretación conforme a la Constitución de todo el ordenamiento penal vigente, principio establecido en el Art.5.1 de la Ley Orgánica del Poder Judicial. ${ }^{42}$

Esta disposición señala expresamente que, "La Constitución es la norma suprema del ordenamiento jurídico, y vincula a todos los Jueces y Tribunales, quienes interpretarán y aplicarán las leyes y Reglamentos según los preceptos y principios constitucionales, conforme a la interpretación de los mismos que resulte de las resoluciones dictadas por el Tribunal Constitucional, con todo tipo de procesos". Agregando que "cuando un órgano judicial considere, en algún proceso, que una norma con rango de ley, aplicable al caso, de cuya validez dependa el fallo, pueda ser contraria a la Constitución, planteará la cuestión ante el Tribunal Constitucional, con arreglo a lo que establece su Ley Orgánica”. Y concluyendo que, "Procederá el planteamiento de la cuestión de inconstitucionalidad cuando por vía interpretativa no sea posible la acomodación de la norma al ordenamiento constitucional (...)".

Así, se puede concluir con estos autores que, tanto desde los valores superiores como desde los principios generales del ordenamiento constitucional se pueden construir principios constitucionales rectores del sistema y del Derecho penal, útiles para la reforma de los mismos. $^{43}$

${ }^{38}$ Al respecto, Cfr. GARCÍA GONZÁLEZ, Rosa, "La igualdad: no discriminación por razón de sexo", RFDUCM (1989), "Diez años de desarrollo constitucional", pp. 425-438.

${ }^{39} \mathrm{Al}$ respecto, Cfr. ARROYO ZAPATERO, Luis, "Prohibición del aborto y Constitución", RFDUCM: "La reforma del Derecho penal”. Monográfico no 3 (1980), pp. 195-222.

${ }^{40} \mathrm{Al}$ respecto, Cfr. BERDUGO GÓMEZ DE LA TORRE, Ignacio, Honor y libertad de expresión. Madrid: Tecnos, 1987; BACIGALUPO, Enrique, "Conflictos de Derechos fundamentales y justificación en los delitos contra el honor" en, DEL MISMO, Principios Constitucionales de Derecho penal, cit. nota $\mathrm{n}^{\circ}$ 31, pp. 183202.

${ }^{41}$ Al respecto, Cfr. BERDUGO GÓMEZ DE LA TORRE, Honor y libertad de expresión, cit. nota ${ }^{\circ}$ 40; VIVES ANTÓN, Tomás, "Sentido y límites de la libertad de expresión" en su obra, La libertad como pretexto, cit. nota $\mathrm{n}^{\circ} 18$, pp. 367-385.

${ }^{42} \mathrm{Al}$ respecto, Cfr. VIVES ANTÓN, "Reforma política y Derecho penal”, cit. nota $\mathrm{n}^{\mathrm{o}} 18, \mathrm{p} .121$ y ss.; DEL MISMO, "Tribunales de justicia y Jurisprudencia Constitucional" en su obra, La libertad como pretexto, cit. nota $\mathrm{n}^{\circ}$ 18, pp. 237-243; BERDUGO/ARROYO/GARCÍA/FERRÉ/SERRANO, Lecciones de Derecho penal, cit. nota $\mathrm{n}^{\circ}$ 8, p. 42; ARROYO ZAPATERO, "Control constitucional del Derecho", cit. nota n ${ }^{\circ}$ 20, pp. 388 y 389.

${ }^{43}$ BERDUGO/ARROYO/GARCÍA/FERRÉ/SERRANO, Lecciones de Derecho penal, cit. nota no 8, p. 42. 


\section{Polit. crim. Vol. 6, № 11 (Junio 2011), Art. 5, pp. 142 - 162. \\ [http://www.politicacriminal.cl/Vol_06/n_11/Vol6N11A5.pdf]}

Más aún, a mi juicio, resulta patente que en los sistemas constitucionales de raíz democrática y social, que tienen ya incorporados estos mandatos constitucionales en forma de valores marco, tanto el desarrollo legal de estos postulados -en todos los ámbitos y con todos los efectos posibles- como su aplicación y cumplimiento, constituye una obligación jurídica suficientemente justificada y legitimada que no puede ni debe soslayarse y menos vulnerarse por meras mayorías políticas coyunturales. Asimismo, resulta sumamente claro que para sistemas jurídico-penales de escaso desarrollo científico, en proceso de democratización o reforma, la opción de incorporar los principios y valores de los derechos fundamentales en la Constitución, a través -por ejemplo- de los principios limitadores del Ius puniendi, constituye una opción sumamente válida y eficaz en favor de la garantía de los derechos de las personas, del establecimiento y sustentación de un Derecho penal democrático y de la propia reforma del sistema penal.

\section{A modo de conclusión: La Constitución y la reforma del sistema jurídico-penal.}

De todo lo señalado se deduce claramente que, tanto la doctrina penal española como la italiana -a diferencia de la alemana-, ${ }^{44}$ han prestado una importante atención a la relación entre el Derecho penal y la Constitución, así como a la influencia del contenido de la norma fundamental sobre el ordenamiento jurídico penal.

De dicha atención científica, y del análisis de las mutuas interrelaciones e influencias recíprocas entre la Constitución y el Derecho penal, ha surgido no sólo un intento de

\footnotetext{
${ }^{44}$ Entre otros autores que se ocupan de esta cuestión en Alemania, además de Schünemann y Roxin, que analiza los efectos que la derivación del concepto de bien jurídico de la Constitución tiene para el Derecho penal, Cfr. ROXIN, Claus, Derecho penal Parte General. Tomo I. Fundamentos. La estructura de la Teoría del delito. Trad. al castellano y notas LUZÓN PEÑA, Diego Manuel, DÍAZ Y GARCÍA CONLLEDO, Miguel, y DE VICENTE REMESAL, Javier. Madrid: Civitas, 1997, pp. 55 y ss., destacan Urs Kindhäuser, Strafrecht Allgemeiner Teil, $2^{\circ}$ ed. Nomos. Baden Baden. 2002; Lothar Kuhlen, Die verfassungskonforme Auslegung von Strafgesetzen, C.F. Müller Verlag, Heidelberg, 2006; y Klaus Tiedemann. Respecto de Kuhlen, se ha realizado una interesante recensión, Cfr. SILVA SANCHEZ, Jesús María. "iHay jueces en Berlin!(y en Karlsruhe)", InDret $\mathrm{N}^{\mathrm{o}} 1$, enero 2007, pp. 399 y ss., en la que se afirma que la propuesta del autor, basada en un análisis de jurisprudencia del TC Alemán, sobre una interpretación de las leyes penales "conforme a la Constitución", constituye una intervención correctora de las posibles desviaciones interpretativas de los Tribunales, una suerte de opción intermedia entre la declaración de inconstitucionalidad de un texto y la defensa de una interpretación de orientada a la Constitución. Por su parte, Tiedemann, en su obra Grundgesetz und Strafrecht, también a través de un análisis de la jurisprudencia del TC Alemán, establece los ámbitos y las cuestiones en los que la interpretación de la Constitución ha contribuido al desarrollo o a la formación del Derecho penal. Esto es: diseño e influencia en la política criminal, no en la dogmática del sistema penal que es asunto de la doctrina penalista y la jurisprudencia penal. Ello, sin perjuicio de que muchas cuestiones fundamentales de la dogmática penal están abiertas a influencias constitucionales, p. ej., el concepto de pena, por lo que el control constitucional es más intenso y compacto en relación con los actos judiciales que establecen, p.ej. una pena de prisión perpetua, que con los actos del legislador. Asimismo, para el autor, el Derecho y la jurisprudencia constitucional afectan más intensamente a la configuración del Derecho procesal penal que al Derecho penal material. Así, a pesar de que no existe una teoría jurídicoconstitucional del delito, debido a las diferencias de valores y fines tanto el tipo como la antijuridicidad y la culpabilidad están abiertas -aunque de forma limitada- a la influencia y valoración constitucional. Al respecto, Cfr. AGUADO CORREA, El principio de proporcionalidad, cit. nota nº 36, pp. 33-34, Nota 7.
} 
DURÁN, Mario. "Constitución y legitimación de la pena. Apuntes teleológicos sobre el rol de la Constitución en el sistema penal".

formular, como ya vimos arriba, un concepto constitucional de delito, ${ }^{45}$ sino también valiosas nociones como la del programa penal de la Constitución ${ }^{46}$ o la del Derecho penal constitucional. $^{47}$

Sin embargo, a mi juicio, lo más relevante es que, sobre la base de estos postulados, se puede señalar que los cambios constitucionales posibilitan claramente la posterior reforma, tanto del código penal respectivo, como del sistema penal en general. ${ }^{48}$

El caso chileno cumple la regla pero al revés. Luego de años intentando la reforma del autoritario pero liberal CP de 1874, para adecuarlo a los nuevos valores democráticos y progresistas de la democracia chilena, con el golpe de Estado de 1973 dicha reforma de detuvo. Más aún, con la implantación de la neo-liberal Constitución de 1980 no fue necesaria ninguna modificación sustancial del Código Penal, salvo la creación de leyes especiales -anti-terrorista, sobre seguridad del Estado y contra el tráfico de drogas- y la reposición del delito de aborto -incluso del terapéutico-, la aplicación efectiva de la pena de muerte, el aumento general de las penas de reclusión -incluso por deudas- y de la prisión preventiva, todo bajo un marcado acento retributivo.

Por ello, como bien se señala, ${ }^{49}$ la estrecha relación existente entre la Constitución y el Derecho penal, surgida bajo el alero del ideal Ilustrado y su empeño por señalar límites al Estado, implica necesariamente que los cambios constitucionales suelan ir acompañados de una reforma correlativa en el Código penal.

Más aún, dichos cambios o reformas son sumamente necesarios y exigibles cuando la nueva Constitución supone una alteración de los presupuestos formales y materiales que determinan el ejercicio de la potestad punitiva. Sobre todo, cuando dicho poder punitivo pasa a ejercerse con el fin de lograr ciertos objetivos, que dependen de la estructura y fines que la comunidad política democráticamente se ha atribuido, con sujeción a determinados limitaciones de forma y contenido, a través de la nueva Constitución, como los fines de la pena.

Así, un cambio constitucional profundo, como el que supone el paso de un Estado autoritario o Liberal-abstencionista a un Estado social y democrático, como es el que por lo demás se espera para nuestro país, no puede dejar de repercutir en el Derecho penal, incluso aunque no se concrete en una reforma directa al Código penal.

\footnotetext{
${ }^{45}$ Al respecto, Cfr. VIVES ANTÓN, Tomás, "Estado de Derecho y Derecho penal” en: DEL MISMO, La libertad como pretexto. Valencia: Tirant lo Blanch, 1995. pp. 92 y ss.; CARBONELL MATEU, Derecho penal: concepto y principios constitucionales, cit. nota $\mathrm{n}^{\mathrm{o}} 12$, p. 21.

${ }^{46}$ Al respecto, Cfr. ARROYO ZAPATERO, "Fundamento y función del sistema penal”, cit. nota n 13 , pp. 97-112.

${ }^{47}$ BERDUGO/ARROYO/GARCÍA/FERRÉ/SERRANO. Lecciones de Derecho penal, cit. nota $\mathrm{n}^{\circ} 8, \mathrm{p} .41$.

48 Al respecto, Cfr. DOLCINI, Emilio, "Principi costituzionali e Diritto penale alle soglie del nuovo millennnio", DIDPP $\mathrm{N}^{\circ} 1$ (1999), pp. 10 y ss.

${ }^{49}$ En este sentido, Cfr. VIVES ANTÓN, Tomás, “Estado de Derecho y Derecho penal”, cit. nota no 45, p. p. 91.
} 
Por esta razón, si el nuevo orden constitucional -con su nuevo sistema de valores y principios- efectivamente desea ser jurídicamente aplicado, ser respetado y legitimado políticamente más allá de la mera validez formal, debe introducirse de forma real y efectiva en el propio sistema penal. Principalmente, a través de la adopción de dichos valores y principios y de la aplicación de los nuevos fines, objetivos e instrumentos que implica la nueva estructura democrática del Estado. Sobre todo porque, generalmente, la entrada en vigor de una nueva constitución plenamente democrática, las reformas efectuadas en la legislación para adecuarla a ella y la inminencia de un nuevo Código penal, acorde con la nueva situación histórico-político que todo esto crea, tiende a cerrar -de forma definitiva- la anterior época legislativa. ${ }^{50}$

Ello, porque, como venimos señalando, desde una óptica sustancial o teleológica se plantea como necesario que, en toda sociedad realmente pluralista y democrática, sea la Constitución política el instrumento jurídico llamado a contener aquellos valores o principios-marco que, consensuados al interior de la misma, deben promover las necesarias reformas penales que posibiliten su positivación en el sistema penal.

De este modo, además, el sistema de valores y principios contenidos en la Constitución debe ser el punto de referencia básico y fundamental de las valoraciones político-criminales que deben guiar cualquier programa de reforma del sistema penal. Más aún, la propia incorporación de la política-criminal a la dogmática penal, que facilita y promueve la reforma misma del sistema, puede hacerse a través de los principios Constitucionales. ${ }^{51}$

Ello, no sólo porque la Constitución configura y ordena los poderes del Estado, estableciendo al mismo tiempo los límites del ejercicio del poder, sino porque, además, asegura la unidad del ordenamiento sobre la base de un orden de valores materiales, que en ella viene expresado, y no sobre simples reglas formales de producción de normas. Estos valores no son pura retórica, ni meros principios programáticos -en el sentido peyorativo del término, esto es, sin valor normativo de aplicación posible- por el contrario, son justamente la base entera del ordenamiento, la que ha de prestar a éste su sentido propio, la que ha de presidir, en fin, toda su interpretación y aplicación. ${ }^{52}$

Además, los principios constitucionales -así concebidos- pueden operar como límites garantísticos a la reforma del sistema penal, al basarse directamente en los derechos fundamentales. Como bien se sostiene, el constitucionalismo, tal como resulta de la positivización de los derechos fundamentales como límites y vínculos sustanciales a la legislación positiva, corresponde a una segunda revolución en la naturaleza del derecho, que se traduce en una alteración interna del paradigma positivista clásico. Si la primera revolución se expresó en la afirmación de la omnipotencia del legislador, es decir, el

\footnotetext{
${ }^{50}$ En este sentido, Cfr. BERDUGO GÓMEZ DE LA TORRE, Ignacio, "Derecho represivo en España durante los períodos de guerra y posguerra", RFDUCM, "La reforma penal", Monográfico no 3 (1980), p. 97. Un exhaustivo análisis al respecto, pp. 99-128.

51 Sobre el valor axiológico de la constitución como marco de referencia valorativo de la política criminal y sobre la selección de los instrumentos para diseñar un programa político-criminal, Cfr. ZÚÑIGA RODRÍGUEZ, Laura, cit. nota $\mathrm{n}^{\mathrm{o}} 15$, pp. 50 y ss. y p.177 y ss. respectivamente.

${ }^{52}$ Cfr. GARCÍA DE ENTERRÍA, Eduardo, La Constitución como norma y el Tribunal Constitucional. $3^{\mathrm{a}}$ Ed. Madrid: Tecnos, 1985, pp. 49, 97 y ss.
} 
DURÁN, Mario. "Constitución y legitimación de la pena. Apuntes teleológicos sobre el rol de la Constitución en el sistema penal".

principio de mera legalidad o de legalidad formal, como norma de reconocimiento de la existencia de las normas, esta segunda revolución se caracteriza por la afirmación del principio de estricta legalidad o legalidad sustancial. O sea, con el sometimiento también de la ley a vínculos ya no sólo formales sino sustanciales impuestos por los principios y derechos fundamentales contenidos en las constituciones. ${ }^{53}$

Estas ideas quedan de manifiesto en la propia Exposición de Motivos de la Ley Orgánica 10/1995, de 23 de noviembre, por la que se aprobó el vigente Código Penal español, donde se afirma que, si se ha llegado a definir el ordenamiento jurídico como conjunto de normas que regulan el uso de la fuerza, puede entenderse fácilmente la importancia del Código Penal en cualquier sociedad civilizada. El Código Penal define los delitos y faltas que constituyen los presupuestos de la aplicación de la forma suprema que puede revestir el poder coactivo del Estado: la pena criminal. En consecuencia, ocupa un lugar preeminente en el conjunto del ordenamiento, hasta el punto de que, no sin razón, se ha considerado como una especie de Constitución negativa. El Código Penal ha de tutelar los valores y principios básicos de la convivencia social. Cuando esos valores y principios cambian, debe también cambiar.

Más aún, la Exposición de Motivos señala que el eje de los criterios en los que se inspira su elaboración, es el de la adaptación positiva del nuevo Código Penal a los valores constitucionales. Destacando que se ha reformado el sistema de penas para intentar alcanzar los objetivos de resocialización que la propia Constitución les asigna; se intenta superar la antinomia entre el principio de intervención mínima y las nuevas necesidades de tutela, eliminando algunas figuras obsoletas y dando acogida a nuevas formas de delincuencia; se da una relevancia especial a la protección de los derechos fundamentales y se intenta avanzar en el cumplimiento del mandato que la Constitución impone a los poderes públicos de promover la igualdad real y efectiva.

De igual forma, en cuanto a las técnicas de elaboración, la Exposición de Motivos, señala que tanto el Código penal como las leyes especiales se hallan jerárquicamente subordinados a la Constitución y obligados a someterse a ella, no sólo por esa jerarquía, sino también por la existencia de un control jurisdiccional de la constitucionalidad.

Por otra parte, esta relación entre el Derecho penal y la Constitución no se agota en la vinculación del Derecho penal a los criterios constitucionales. Además, debe destacarse que en el marco de esta especial relación entre la Constitución democrática y social se acude al Derecho penal precisamente para proteger la Constitución, como lo demuestra la inclusión en el Código Penal Español de 1995 del Título XXI (Arts. 472 y ss.) dedicado a los "Delitos contra la Constitución", título que constituye una de las novedades que justifica el calificativo de Código Penal de la Democracia, al reafirmar con su existencia la seguridad que deben poseer los ciudadanos de que el Estado ajusta su actuación a la Constitución aprobada democráticamente, respetando con ello no sólo la soberanía popular sino los contenidos y la legitimidad de la misma.

\footnotetext{
${ }^{53}$ Cfr. FERRAJOLI, Luigi, Derechos y garantías. La ley del más débil. Prólogo de Perfecto Andrés Ibáñez. IBAÑEZ, Perfecto Andrés; GREPPI, Andrea (Trads.), Madrid: Trotta, 1999, p. 66.
} 
Polit. crim. Vol. 6, № 11 (Junio 2011), Art. 5, pp. 142 - 162.

[http://www.politicacriminal.cl/Vol_06/n_11/Vol6N11A5.pdf]

De esta forma, a mi juicio, junto con destacar la importancia que una Constitución social y democrática tiene respecto de la fundamentación del Derecho penal y su reforma, queda al menos someramente justificado el establecimiento de un criterio teórico-doctrinal que tenga por finalidad justificar y legitimar la aplicación de la pena, fundado en los valores y los principios que la Constitución democrática propugne y pretenda instaurar en el sistema penal y en el Derecho penal en particular.

\section{BIBLIOGRAFÍA}

AGUADO CORREA, Teresa, El principio de proporcionalidad en Derecho penal. Madrid: Edersa, 1999.

ÁLVAREZ GARCÍA, Fernando, "Bien jurídico y Constitución” CPC (1991), pp.18 y ss.

ANGIONI, Francesco, "Beni costituzionali e criteri orientativi sull'area dell'illecito penale'

" en, STILE, Alfonso (a cura di) Bene Giuridico e Riforma della parte speciale. Napoli: Jovene, 1985, pp. 57 y ss.

ARROYO ZAPATERO, Luis, "Fundamento y función del sistema penal: el programa de la Constitución”, RJCLM N 1 (1987), pp. 97 y ss.

, "Control constitucional del Derecho y de la justicia penal", $C P C$ No XVII (1982), pp. 285 y ss.

, "Prohibición del aborto y Constitución" RFDUCM, "La reforma del Derecho penal". Monográfico no 3 (1980), pp. 195 y ss.

BACIGALUPO, Enrique, "La jerarquía constitucional del principio de culpabilidad" en, DEL MISMO, Principios Constitucionales de Derecho penal. Buenos Aires: Hammurabi, 1999, pp. 137 y ss.

, "Protección de los Derechos fundamentales por la jurisdicción constitucional y por el poder judicial” en, DEL MISMO, Principios Constitucionales de Derecho penal. Buenos Aires: Hammurabi, 1999, pp. 13 y ss.

, "El principio de legalidad como tarea inconclusa" en, DEL MISMO, Principios Constitucionales de Derecho penal. Buenos Aires: Hammurabi, pp. 43 y ss.

, "La garantía del principio de legalidad y la prohibición de la analogía en el Derecho penal" en, DEL MISMO, Principios Constitucionales de Derecho penal. Buenos Aires: Hammurabi, pp. 72 y ss.

"La problemática Constitucional de las leyes penales en blanco" en, DEL MISMO, Principios Constitucionales de Derecho penal. Buenos Aires: Hammurabi, pp. 99 y ss.

, "Conflictos de Derechos fundamentales y justificación en los delitos contra el honor" en, DEL MISMO, Principios Constitucionales de Derecho penal. Buenos Aires: Hammurabi, pp. 183 y ss.

BARBERO SANTOS, Marino, Política y Derecho Penal en España. Madrid: Tucar Ediciones, 1977.

BERDUGO GÓMEZ DE LA TORRE, Ignacio, Honor y libertad de expresión. Madrid: Tecnos, 1987.

, "Derecho represivo en España durante los períodos de guerra y posguerra", RFDUCM, "La reforma penal”, Monográfico No 3 (1980), pp. 97 y ss. 
DURÁN, Mario. "Constitución y legitimación de la pena. Apuntes teleológicos sobre el rol de la Constitución en el sistema penal".

BERDUGO/ARROYO/GARCÍA/FERRÉ/SERRANO, Lecciones de Derecho penal. PG. $2^{\mathrm{a}}$ Ed. Barcelona: Praxis, 1999.

BRICOLA, Franco, “Teoria generale del reato" en, Novissimo Digesto Italiano, vol. XIV. Torino: Utet, 1973, .pp. 7-93 y en sus, Scritti di Diritto Penale. vol.I, T.I. Milano: Giuffrè, 1997, pp. 539 y ss.

BUENO ARÚS, F. "Las normas penales en la Constitución española de 1978", Doctrina Penal No 8 (1979), pp. 821 y ss.

BUStOS RAMÍREZ, Juan. Manual de Derecho Penal. Parte General. $3^{\mathrm{a}}$ edición. Ariel. Barcelona, 1989. p. 394 y ss.

BUSTOS RAMÍREZ, Juan - HORMAZÁBAL MALARÉE, Hernán, "Pena y Estado", Papers $\mathrm{N}^{\mathrm{0}} 13$, pp. 97 y ss.

, Lecciones de Derecho penal. Vol. I. Madrid: Trotta, 1997.

CARBONELL MATEU, Juan Carlosm Derecho penal: concepto y principios constitucionales. $3^{\text {a }}$ Edic. Valencia: Tirant Lo Blanch, 1999.

CÓRDOBA RODA, Juan, "La pena y sus fines en la constitución Española de 1978", Papers $\mathrm{N}^{\mathrm{o}} 13$, pp. 129 y ss.

DE SOLA DUEÑAS, Ángel, "Desarrollo democrático y alternativas político criminales", Papers $\mathrm{N}^{\mathrm{o}} 13$, pp. 215 y ss.

DOLCINI, Emilio, "Principi costituzionali e Diritto penale alle soglie del nuovo millennnio", DIDPP N $\mathrm{N}^{\mathrm{o}} 1$ (1999), pp.10 y ss.

DONINI, Massimo, "Un Derecho penal fundado en la carta constitucional: razones y límites. La experiencia Italiana" en: VV.AA. Responsa Iurisperitorum Digesta. Salamanca: Edic. Universidad. Vol. II, 2001, pp. 223 y ss.

, Il volto attuale dell'illecito penale. La democracia penale tra differenzizione e sussidiarietà. Milano: Giuffrè, 2004, pp. 61 y ss.

, Teoria del reato. Una introduzione. Padova: Cedam, 1995;

"Dogmatica penale e política criminal a orientamento costituzionalistico. Conoscenza e controllo critico delle secelte di criminalizzazione", Dei delitte e delle pene $\mathrm{N}^{\mathrm{o}} 3$ (1998), pp. 37 y ss.

DURAN MIGLIARDI, Mario, Introducción a la Ciencia jurídico-penal contemporánea. Santiago: Ediciones jurídicas de Santiago, 1996.

, "El Derecho penal del enemigo. Formulación y observaciones críticas en el contexto del debate sobre la modernización y expansión del Derecho penal" en: CANCIO MELIÁ, Manuel (Ed. y Coord.), Derecho penal del enemigo. El discurso penal de la exclusión. Buenos Aires- Montevideo: Editoriales B de F; Madrid: Edisofer, 2006, pp. 725 y ss.

,"Prevención General Positiva o de la Integración. Concepto y función" en: Problemas Actuales del Derecho Penal. Seminario de Derecho Penal Universidad de Salamanca. Libro Homenaje al profesor Dr. Ignacio Berdugo Gómez de la Torre. Santiago: Editorial Jurídica de Santiago, 2007, pp. 269 y ss.

"Análisis político-criminal de la ley de responsabilidad penal adolescente y sus modificaciones" en: Estudios de Ciencias Penales: Hacia una racionalización del Derecho Penal. IV Jornadas Nacionales de Derecho Penal y Ciencias Penales, Valdivia, 2007, Santiago de Chile: Legal Publishing, 2008, pp. 275 y ss. 
Polit. crim. Vol. 6, № 11 (Junio 2011), Art. 5, pp. 142 - 162.

[http://www.politicacriminal.cl/Vol_06/n_11/Vol6N11A5.pdf]

, "Prevención especial e ideal resocializador. Concepto, evolución y vigencia en el marco de la legitimación y justificación de la pena", Revista de Estudios Criminológicos y Penitenciarios $\mathrm{N}^{\mathrm{o}} 13$ de Gendarmería de Chile (Diciembre 2008), pp. 57 y ss.

ESCRIVÁ GREGORI, José María, “Algunas consideraciones sobre Derecho penal y Constitución", Papers $\mathrm{N}^{\mathrm{o}} 13$, pp. 147 y ss.

FERRAJOLI, Luigi, Derecho y Razón. Teoría del Garantismo Penal. Madrid: Trotta S.A., 1995.

, Derechos y garantías. La ley del más débil. Prólogo de Perfecto Andrés Ibáñez. IBAÑEZ, Perfecto Andrés / GREPPI, Andrea (Trads.), Madrid: Trotta, 1999.

GARCÍA ARÁN, Mercedes, “Constitución y Derecho penal, veinte años después” en: ARROYO, L.-BERDUGO, I. (Dir). Homenaje al Dr. Marino Barbero Santos. Cuenca: U. De Castilla La Mancha-U. De Salamanca, 2001, pp. 285 y ss.

GARCÍA DE ENTERRÍA, Eduardo, La Constitución como norma y el Tribunal Constitucional. $3^{\text {a }}$ Ed. Madrid: Tecnos, 1985.

GARCÍA GONZÁLEZ, Rosa, "La igualdad: no discriminación por razón de sexo" en: VV.AA. RFDUCM (1989), "Diez años de desarrollo constitucional", pp. 425 y ss.

GARCÍA-PABLOS, Antonio, “La 'resocialización' del delincuente.¿Un Mito?” en: DEL MISMO, Problemas actuales de la criminología. Madrid: Publicación del Instituto de criminología de la U. Complutense de Madrid, 1984, pp. 203 y ss.

, "La supuesta función resocializadora del Derecho Penal: utopía, mito y eufemismo", $A D P C P$, T. XXXII, fascículo III (1979), pp. 645 y ss.

GARCÍA RIVAS, Nicolás, El poder punitivo en el Estado democrático de Derecho. Cuenca: U. de Castilla-La Mancha, 1996.

GONZÁLEZ RUS, Juan José, Bien jurídico y Constitución. (Bases para una teoría). Madrid: Fundación Juan March, 1983, pp. 23 y ss.

HABERMAS, Jürgen. Facticidad y validez. Sobre el derecho y el Estado democrático de derecho en términos de teoría del discurso. Introd. y Trad. sobre la $4^{\circ}$ edic. revisada de Manuel Jiménez Redondo. Madrid: Trotta, 2001.

HORMAZÁBAL MALARÉE, Hernán, Bien jurídico y Estado social y democrático de Derecho. (El objeto protegido por la norma penal). Barcelona: PPU, 1991.

JESCHECK, Hans-Heinrich, Tratado de Derecho Penal. Parte General. Trad. MANZANARES SAMANIEGO, José Luis. Granada: Comares, 1993.

KINDHÄUSER, Urs. Strafrecht Allgemeiner Teil, $2^{\circ}$ ed. Nomos. Baden Baden. 2002.

KUHLEN, Lothar. Die verfassungskonforme Auslegung von Strafgesetzen, C.F. Müller Verlag, Heidelberg, 2006.

LÓPEZ BARJA DE QUIROGA, Jacobo, “Constitución y Derecho penal”, $C P C \mathrm{~N}^{\mathrm{o}}$ 31-33 (1987), pp. 55 y ss.

MAGARIÑOS, Mario, "Hacia un Criterio Para la Determinación Judicial de la Pena". En: AA.VV., Determinación Judicial de la Pena, Buenos Aires: Editores del Puerto, 1993, pp. 74 y ss.

MIR PUIG, Santiago, "Función de la pena y teoría del delito en el Estado social y democrático de Derecho" en: DEL MISMO, El Derecho penal en el Estado social y democrático de Derecho. Barcelona: Ariel, 1994, pp. 31 y ss. 
DURÁN, Mario. "Constitución y legitimación de la pena. Apuntes teleológicos sobre el rol de la Constitución en el sistema penal".

MOCCIA, Sergio, Il Diritto penale tra essere e valore. Funzione sistematica teleologica. Napoli: ESI, 1992.

, "Función sistemática de la política criminal. Principios normativos para un sistema penal orientado teleológicamente" en: SCHÜNEMANN, B.-De FIGUEIREDO DIAS, J. (Coords.) SILVA SÁNCHEZ, J.M. (Ed. Española) Fundamentos de un Sistema Europeo del Derecho penal. Libro-Homenaje a Claus Roxin. Barcelona: Bosch, 1995, pp. 73 y ss.

MUÑOZ CONDE, Francisco, "La resocialización del delincuente. Análisis y crítica de un mito", $C P C \mathrm{~N}^{\mathrm{o}} 7$ (1979).

, Derecho Penal y Control Social. Jerez de la Frontera: Fundación Universitaria de Jerez, 1986.

MUÑOZ CONDE, Francisco; GARCÍA ARÁN, Mercedes, Derecho penal PG. Valencia: Tirant Lo Blanch, 1994.

PÉREZ LUÑO, Antonio, Derechos Humanos, Estado de Derecho y Constitución. $4^{\mathrm{a}}$ Ed. Madrid: Tecnos, 1991.

QUINTERO OLIVARES, Gonzalo, “Determinación de la Pena y Política criminal”, CPC No 4 (1982), pp. 49 y ss., esp. p. 52.

Doctrina Penal, Buenos Aires, 1982.

"Política criminal y determinación de la pena", , Represión penal y Estado de Derecho. Barcelona:

Dirosa, 1976.

ROXIN, Claus, "Reflexiones Político-Criminales Sobre el Principio de Culpabilidad", en: DEL MISMO, Culpabilidad y Prevención en el Derecho Penal. Trad. Francisco Muñoz Conde. Madrid: Reus S.A., 1981, pp. 46 y ss.

, "La Determinación de la Pena a la Luz de la Teoría de los fines de la Pena”, en: DEL MISMO, Culpabilidad y Prevención en el Derecho Penal. Trad. Francisco Muñoz Conde. Madrid: Reus S.A., 1981, pp. 46 y ss.

, Derecho penal Parte General. Tomo I. Fundamentos. La estructura de la Teoría del delito. Trad. al castellano y notas LUZÓN PEÑA, Diego Manuel, DÍAZ Y GARCÍA CONLLEDO, Miguel, y DE VICENTE REMESAL, Javier. Madrid: Civitas, 1997, pp. 55 y ss.

SILVA SANCHEZ, Jesús María, "La teoría de la determinación de la pena como sistema (Dogmático): Un primer esbozo". InDret No 2 (2007), pp. 4 y ss. , “Hay jueces en Berlín! (y en Karlsruhe)”. InDret $\mathrm{N}^{\mathrm{o}} 1$ (2007), pp.399 y ss.

TERRADILLOS BASOCO, Juan, "Constitución y ley penal. La imposible convergencia”, RFDUCM T. 10-11 (1986), pp. 651 y ss.

TERRADILLOS BASOCO, Juan, "La satisfacción de necesidades como criterio de determinación del objeto de tutela jurídico-penal”, RFDUCM No 63 (1981), pp. 123 y SS.

TIEDEMANN, Klaus, "Constitución y Derecho penal”, REDC No 33 (1991), pp. 145 y ss. VV.AA., RFDUCM, "Diez años de desarrollo constitucional". Monográfico no 15 (1989). VV.AA., "Il Codice Rocco cinquant'anni dopo" en: La Questione Criminale, 1981.

VIVES ANTÓN, Tomás, "Reforma política y Derecho penal" en: DEL MISMO, La libertad como pretexto. Valencia: Tirant Lo Blanch, 1995, pp. 71 y ss. 
Polit. crim. Vol. 6, No 11 (Junio 2011), Art. 5, pp. 142 - 162.

[http://www.politicacriminal.cl/Vol_06/n_11/Vol6N11A5.pdf]

, "Estado de Derecho y Derecho penal" en: DEL MISMO, $L a$ libertad como pretexto. Valencia: Tirant lo Blanch, 1995, pp. 92 y ss. , "Sentido y límites de la libertad de expresión" en: DEL MISMO, La libertad como pretexto. Valencia: Tirant Lo Blanch, 1995, pp. 367 y ss. ,"Reforma política y Derecho penal" en: DEL MISMO, La libertad como pretexto. Valencia: Tirant Lo Blanch, 1995, pp. 121 y ss.

,"Tribunales de justicia y Jurisprudencia Constitucional" en:

DEL MISMO, La libertad como pretexto. Valencia: Tirant Lo Blanch, 1995, pp. 237 y ss.

ZIFFER, Patricia, "Consideraciones Acerca de la Problemática de la Individualización de la Pena", en: AA.VV., Determinación Judicial de la Pena, Buenos Aires: Editores del Puerto, 1993, p. 91.

ZÚÑIGA RODRÍGUEZ, Laura, Política criminal. Madrid: Colex, 2001. 